Western University Scholarship@Western

1997

\title{
Rational Nonprofit Entrepreneurship
}

Marc Bilodeau

Al Slivinski

Follow this and additional works at: https://ir.lib.uwo.ca/economicsresrpt

Part of the Economics Commons

Citation of this paper:

Bilodeau, Marc, Al Slivinski. "Rational Nonprofit Entrepreneurship." Department of Economics Research Reports, 9709. London, ON: Department of Economics, University of Western Ontario (1997). 
ISSN:0318-725X

ISBN:0-7714-2029-3

\title{
RESEARCH REPORT 9709
}

\section{Rational Nonprofit Entrepreneurship}

\author{
by \\ Marc Bilodeau Al Slivinski \\ ECONOHICS REFERENCE CENTRE \\ NOV 171997 \\ UNIVERSITY OF WESTERN OITERII
}

October 1997

\author{
Department of Economics \\ Social Science Centre \\ University of Western Ontario \\ London, Ontario, Canada \\ N6A 5C2 \\ econref@sscl.uwo.ca
}




\title{
Rational Nonprofit Entrepreneurship*
}

\begin{abstract}
This paper derives the decision to found a nonprofit firm as the equilibrium outcome of a multistage game among individuals who would like a public good to be provided. The model predicts that if individuals will voluntarily contribute towards provision of the public good. then it is in the private interest of the entrepreneur to impose a non-distribution constraint on herself by founding a nonprofit firm. This decision aiso results in greater voluntary contributions than if the firm is proprietary.
\end{abstract}

Marc Bilocieau

Lniversité de Sherbrooke

Département d'Économique

L'niversité de Sherbrooke

Sherbrooke. PQ

Canada J1K 2RI

mbilodea $\underline{g}$ courrier .usherb.ca

\author{
Al Slivinski \\ Department of Economics \\ U'niversity of W'estern Untario \\ London. Unt. \\ Canada . $\mathrm{N} 6 \mathrm{~A} 5 \mathrm{C} 2$ \\ aslivins $\hat{\mathrm{g}} \mathrm{julian.uwo.ca}$
}

The authors have benefitted from comments on previous drafts from many conference and workshop participants, particularly Robin Cowan, Jim Davies, Ig Horstmann, Bart Lipman, Glenn MacDonald, Mlotty Perry, Richard Steinberg and two anonymous referees. 


\section{Introduction}

Why would anyone invest time and money to found a nonprofit enterprise ${ }^{\text {? }}$ ? More specifically, how could it be rational for the inciividual who founds an enterprise and might still control it to deny herself the opportunity to appropriate the fruits of her skills and efforts? Yet nonprofit firms are founded every day. For example, from 1987 to $1989,110,000 \mathrm{new}$ charitable organizations were founded in the U.S.A. ${ }^{2}$ Nonprofit firms constitute a significant sector of most modern economies and appear in a wide variety of industries. providing everything from health and educational services to charitable activities and entertainment. For example, in 1990, nonprofit firms accounted for $6.8 \%$ of total national income in the U.S.A. and $4.2 \%$ of all firms ${ }^{3}$.

The starting point for our investigation is the observation that many nonprofit firms receive a substantial part of their revenues in the form of donations and use them to provide public goods. Universities, medical research institutions and the United Way are obvious examples, but hospitals. museums, little league sports teams, and theatrical or musical companies can also be viewed as providing a public good since their existence makes available to an entire community a flow of services which consumers value. This option-value is a public good and individuals may be willing to contribute voluntarily toward its provision ${ }^{4}$. $\overline{1}$

A nonprofit enterprise is a firm which has no residual claimants. It can be profit-making in the sense that it can show and accumulate any level of surplus from its activities, but is subject to a legally enforced non-distribution constraint (NDC) on its net cash flows. Throughout this paper, we will use the word 'profit' to refer to any difference between the firm's revenues and expenditures, even if the revenues are constituted entirely of voluntary donations received by the firm.

2

3

Source: Hogdkinson et al.(1992). p.12.

4

Source: Hodgkinson et al.(1992), p.4.

There is a large economic literature on voluntary contributions to public goods, e.g., Bernheim(1986), 
To explain why nonprofit firms are more likely than proprietary firms to receive donaticns, Fama and Jensen(1983) argue that general donations pose a particular agency problem to proprietary firms. Individuals may want to give a firm money to finance the production of a public good but if the firm is proprietary they have no assurance that their contributions will be used for this purpose because they do not receive an immediate quid pro quo for their gifts. By comparison when the firm is nonprofit, the non-distribution constraint provides assurance to donors that their contributions will not be expropriated by the firm's residual claimants. So nonprofit firms have a raison d'être in situations in which a public good is to be provided privately through voluntary contributions ${ }^{5}$.

However, whether a nonprofit firm could fulfill a socially desirable economic role does not explain why an individual could find it in his private interest to found such a firm, especially if there are costs in terms of time, energy and money to being a nonprofit entrepreneur. To understand nonprofit firm formation, we need models in which a rational self-interested entrepreneur founds a nonprofit firm, not because this is socially optimal in some sense, but because it is in her best interest to do so.

One possibility would be to assume that the non-distribution constraint is either not perfectly enforceable or only restricts the form rather than the amount of profit distribution, so that a nonprofit manager could at least partially circumvent it by using some of the firm's Bergstrom, et.al.(1986), Andreoni(1988),(1989), Sugden (1982), and Varian(1994).

The idea that nonprofit firms arise to provide public goods is due to Weisbrod(1975). Other rationales for the existence of nonprofit firms have been proposed in the literature. For example, Hansmann(1980) suggests that when the quality of a firm's output is hard to observe, a nonprofit firm may be more trustworthy because the inability to claim profits removes an incentive to defraud customers. Formalizing this idea, Easley and O'Hara(1983) show that a nonprofit firm can be the solution to an optimal social contracting problem with aymmmetric information. James and Rose-Ackerman(1986), Powell(1987), Gassler(1987) and Steinberg(1993) provide surveys of the economic literature on nonprofit firms. 
net revenues for 'perks' or an inflated salary. Using this approach. Eckel and Steinberg(1993) show that a manager who is more skilled at cheating or who prefers perks to cash might be better off seeking employment in-or founding - a nonprofit rather than a proprietary enterprise. While there is surely some truth to the hypothesis that the non-distribution constraint is not always perfectly enforced or only restricts the form of profit distribution. this begs the question as to why anyone would voluntarily impose such a constraint in the first place ${ }^{6}$. After all. the founder of a proprietary firm can also pay inflated salaries and provide perks to herself and her managers. and can do so legally. To understand nonprofit firm formation. we need models in which it is in the entrepreneur's own interest to impose this constraint on herself. Of course, ex-post, once donations have been collected or profits realized, it may never be in the entrepreneur's interest to obey the non-distribution constraint, but at least it should be in her interest ex-ante to impose it. Would anyone found a nonprofit enterprise even if they knew that the non-distribution constraint disallowed all forms of surplus distribution and would be strictly enforced?

A second possibility mould be to assume that there are returns to being a nonprofit entrepreneur which do not accrue to the founder of a proprietary firm. For example, the entrepreneur's motivations could include the desire for status or recognition. or feelings of 'warm glow': which she would not receive if she founded a proprietary enterprise. Without denying that these factors could influence the choice of whether to found a proprietary or nonprofit enterprise. we wish to ask whether an ordinary individual who only cares about 6

In some countries, like the U.S.A., nonprofit firms receive favourable tax treatment and in some cases outright tax exemption if they meet certain requirements. So tax avoidance could be a reason for the formation of some nonprofits. In the present paper, we abstract away from the tax system and do not analyze this possibility. 
his consumption of a public and a private good would rationally choose to found a nonprofit firm.

To answer this question. we build a model in which an entrepreneur can choose to found either a nonprofit or proprietary firm to produce a public good. It predicts that in situations in which the entrepreneur would herself contribute toward the public good's provision and in which the firm would also receive voluntary contributions from others, it will be in the entrepreneur's own interest to found a nonprofit rather than a proprietary enterprise, because the non-distribution constraint induces greater contributions from the public. and this in turn allows her to contribute less herself. We thus provide a simple explanation for the commonplace observation that virtually all firms receiving private donations are nonprofit. Since a nonprofit firm will elicit a higher level of total private donations than would an otherwise identical proprietary firm, there is also an efficiency gain when these enterprises are nonprofit instead of proprietary.

\section{Model}

\subsection{The Institutional Context}

Consider a group of individuals who have preferences over commodity bundles consisting of their own private consumption. and the level of provision of a non-excludable public good. ${ }^{7}$ Suppose, however, that initially there is no institution engaged in producing the public good. In particular, government expenditures on the public good are assumed to be zero. ${ }^{8}$ Then 7

If the good in question is, for example, the building of a new hospital wing or the founding of a theater company, then some or all of the goods and services such a facility uitimately provides may be excludable. However, so long as individuals anticipate future receipt of surplus from the existence of such a facility, (even if its services will be charged for), the facility itself has a non-excludable public good aspect and individuals might want to contribute voluntarily to insure it is made available. Those who see no value in the existence of the facility will of course not voluntarily contribute funds for its establishment. 
even if individuals wanted to voluntarily contribute toward its provision. there is no one to collect such contributions and use them to produce the public good. If any of the public good is to be provided, then someone must organize its production.

We assume that doing this requires someone-an entrepreneur-to set up a firm. A decision that must be made by the entrepreneur at the outset is whether to incorporate this firm as 'nonprofit' or as 'proprietary'. Since part of our purpose is to determine whether it can be in an entrepreneur's self-interest to impose a non-distribution constraint on herself, we assume that this non-distribution constraint is perfectly enforced. By assumption. the entrepreneur's only motivation is to maximize the utility she derives from her consumption of private and public goods. just like everyone else. It is only this role as owner/operator of the firm that provides the public good which distinguishes her from other individuals in the population.

Once a firm has been set up, the next phase in the provision process is to gather funds to cover the costs of producing the public good. The simplest way to model voluntary provision of a public good is to assume that all individuals contribute simultaneously. However. this simple model cannot account for the fact that the entrepreneur controls the fund-raising process. She collects the money others give her and this gives her certain prerogatives not available to others, perhaps including the option of keeping some of it for herself. These prerogatives cannot be captured in a model in which the entrepreneur is only one individual contributing simultaneously with all others.

As founder of the firm, an entrepreneur always has the option to contribute some of her

\footnotetext{
The politically determined government provision of some public goods does not generally eliminate completely the demand for private supplementation when individuals have heterogeneous preferences. See Weis brod(1975). We assume that the government does not provide any of this public good to simplify the analysis.
} 
As founder of the firm. an entrepreneur always has the option to contribute some of $t . r$ own private funds to the firm before appealing to the public for donations ${ }^{9}$. We model risis by allowing the entrepreneir to contribute before everyone else if she so chooses. Further, as the person controlling when and how the money collected will be used, she also has the option of contributing again after the fund-raising campaign is over, if she feels that a higher level of provision is preferable. Another prerogative of the entrepreneur is choosing the production technology and the quantity of the public good to be produced by her firm. To abstract from issues of output quality, X-efficiency and agency problems within the firm. we assume that there is only one production process for the public good and that output quality and costs of production are certain and immediately observable by everyone. This means that once everyone has contributed, the only decision left to the entrepreneur is how much of the public good to provide with the money collected by the firm. In particular, if her firm is proprietary, she could choose to produce less of the public good than would be possible with the funds collected, and appropriate the residual to increase her private consumption. We model this by allowing the entrepreneur to contribute again. positively or negatively (if the firm is proprietary), after everyone else.

This model is intended to capture the essence of what entrepreneurs actually do. Whether proprietary or nonprofit, entrepreneurs are individuals who 'found' new enterprises and decide how they operate. It is shown below that in this extremely stark setting (the nondistribution constraint is perfectly enforced, there are no non-pecuniary rewards to nonprofit entrepreneurship, no issues of asymmetric information between the firm and others, and 9

For simplicity, we assume that the entrepreneur does not raise funds in the capital market, and does not receive government grants. 
no scope for influencing the characteristics of the output) it is in a rational entrepreneur's self-interest to found a nonprofit firm to produce the public good.

\subsection{Formalization}

Consider a community of $n+1$ individuals. labelled $i=0.1, \ldots, n$. Let $w_{i}>0$ denote $i$ s wealth. $x_{i}$ be $i$ s private consumption. and $Z$ be the level of provision of some public good. Assume that preferences can be represented by continuous, strictly quasi-concave utility functions $U_{i}\left(x_{i}, Z\right)$ for all $i$ and that both goods are normal. Let $d_{i}$ be $i$ ss contribution to the public good producing firm. $D=\sum_{i \in N} d_{i}$ be the sum of all contributions. and $D_{-i}=$ $D-d_{i}$ be the total contributions by everyone except $i$. Let $F(Z)$ be the level of donations required to produce $Z$ units of the public good and assume that the cost function $F(\cdot)$ is continuous, strictly increasing and convex. Without loss of generality, we will from now on write individual utility functions as $u_{i}\left(x_{i}, D\right)=U_{i}\left(x_{i}, F^{-1}(D)\right)$. The convexity of $F(\cdot)$ guarantees that the functions $u_{i}(\cdot)$ are quasi-concave in $x_{i}$ and $D$.

We postulate the following sequence of actions:

1. Individuals choose simultaneously whether or not to organize the production of the public good. The individual who so volunteers is called the entrepreneur. If no one volunteers, no public good is provided.

2. The entrepreneur elects to found either a nonprofit or a proprietary enterprise to produce the public good.

3. The entrepreneur may invest some of her private wealth in the firm she has founded before soliciting voluntary contributions from the general public. 
4. After observing the entrepreneur's actions. other members of the community contribute simultaneously to the public good producing enterprise.

j. The entrepreneur may make a final cuntribution (possibly negative if the firm is proprietary), and then produces the public good using all the funds received by her firm.

This sequence of decisions defines a multistage game with observed actions in which the strategy sets include the choices $\{$ volunteer. do not volunteer $\}$ and $\{$ proprietary, nonprofit $\}$ in stages 1 and 2, respectively. In stage 3. the entrepreneur, who will be designated from now on as individual 0 , chooses an initial contribution $d_{0} \in\left[0, w_{0}\right]$. In stage 4. everyone else simultaneously chooses a contribution level $d_{i}$, knowing $d_{0}$ and knowing whether the firm is proprietary or nonprofit. Finally, in stage 5, the entrepreneur chooses whether to add (or subtract, if the firm is proprietary) an additional amount $e$, knowing what has been contributed already and whether she is subject to a non-distribution constraint.

\section{Equilibrium strategies}

Before proceeding, it will be useful to restate the benchmark results for the situation in which a simultaneous-contributions game determines the level of public goods provision. Let

$$
h_{i}(y)=\arg \max _{D \in[0, y]}\left\{u_{i}(y-D, D)\right\}
$$

be $i$ s preferred level of expenditures on the public good out of any sum of money, $y . h_{i}(\cdot)$ is then $i$ 's Engel curve, and normality of both goods ensures that it's derivative lies strictly between zero and one. For convenience, assume that $h_{0}(\cdot)$ is concave. The equilibrium contribution levels in such a game will be $d^{s}=\left(d_{0}^{s}, d_{1}^{s}, \ldots, d_{n}^{s}\right)$, where

$$
d_{i}^{s}=\max \left\{0, h_{i}\left(w_{i}+D_{-i}^{s}\right)-D_{-i}^{s}\right\} \quad i=0,1, \ldots, n
$$


When both $x_{i}$ and $Z$ are normal for all $i$. Bergstrom et. al.(1986) show that $d^{s}$ is unique. While it is not essential to our analysis. we assume that $d_{i}^{s}>0$ for all $i$ for simplicity. Figure 1 illustrates this equilibrium when there are only two individuals. The equilibrium of a simultaneous contributions game would be at $S$ where the two reaction functions given by (1) intersect, contributions are $d_{0}^{s}$ and $d_{1}^{s}$ respectively; and total provision is $D^{s}$. IVe restate this result only because the level of contribution $d_{i}^{s}$ will be referred to later in the analysis. In particular. we do not imply by this that the entrepreneur could choose to set up a simultaneous contributions game instead of a multistage game.

\subsection{The entrepreneur has the final word}

To determine the subgame perfect equilibria of this game, we begin by analyzing the behavior of the entrepreneur ${ }^{10}$ in the last stage. Upon reaching this stage, the entrepreneur has already contributed $d_{0} \geq 0$, and the public has contributed $D_{-0}=\sum_{j=1}^{n} d_{j}$.

If the enterprise is proprietary, the entrepreneur's only equilibrium strategy is to contribute

$$
e^{p}\left(d_{0}, D_{-0}\right)=\max \left\{-\left(D_{-0}+d_{0}\right), h_{0}\left(w_{0}+D_{-0}\right)-\left(D_{-0}+d_{0}\right)\right\}
$$

That is, she contributes the difference between the level of expenditures she considers optimal, $h_{0}\left(w_{0}+D_{-0}\right)$, and what she and the public have already contributed. The entrepreneur is in a situation similar to that of a follower in a Stackelberg game, the only difference being that she may already have contributed some amount $d_{0}$ earlier. In Figure 1. for any level of contribution by the other, she would choose $e^{p}($.$) such that the final level of provision is$ 10

To avoid unnecessary complexity, only the analysis of the subgames in which only one entrepreneur has volunteered is presented here. It is shown below that in any subgame perfect equilibrium, one and only one individual will found a firm. 


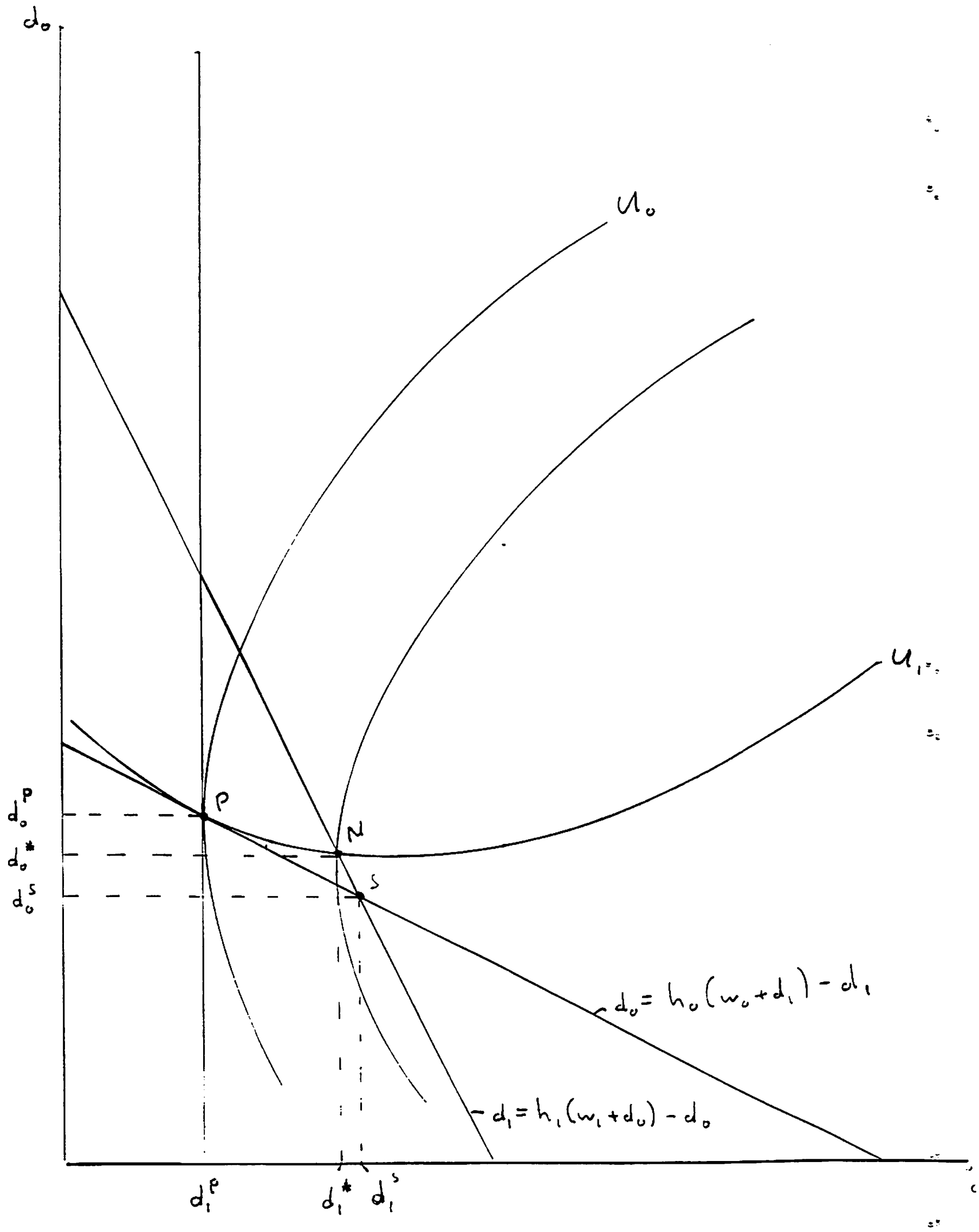

Figure 1 
$h_{0}\left(w_{0}+d_{1}\right)$ on her reaction function. Note that $\epsilon^{P}($.$) may be negative î h_{0}\left(w_{0}+D_{-0}\right)<D$. in which case the entrepreneur nould choose to repossess some of her initial contribution or even to appropriate for her personal consumption some or all of the donations made by others to the enterprise.

If instead the firm is nonprofit. her only equilibrium strategy is to contribute

$$
e^{n}\left(d_{0}, D_{-0}\right)=\max \left\{0, h_{0}\left(w_{0}+D_{-0}\right)-\left(D_{-0}+d_{0}\right)\right\}
$$

The non-distribution constraint prevents the entrepreneur from appropriating the donations of others and from reneging on her own initial contribution. This means that in Figure 1, the entrepreneur would bring the final level of provision up to $h_{0}\left(w_{0}+d_{1}\right)$ if vector $\left(d_{0}, d_{1}\right)$ is below her reaction function, but cannot bring it down if it is above it. She would then choose $e^{n}()=$.0 and all the funds collected so far would be used to provide the public good. Note then that at this stage, for any given values of $D_{-0}, d_{0}$, the entrepreneur cannot be better off from being subjected to the non-distribution constraint.

Equation (2) illustrates the agency problem outlined by Fama and Jensen(1983) that general donations pose to a proprietary firm. Individuals may want to give it money to finance the production of a public good but if the firm is proprietary they have no assurance that their contributions will be used for this purpose. By comparison when the firm is nonprofit, the non-distribution constraint assures individuals that each dollar they contribute will increase the expenditures earmarked for the public good's production by a dollar. provided of course that the non-distribution constraint is binding on the entrepreneur. 


\subsection{The public knows what she's up to}

In Stage 4 the $n$ other community members contribute simultaneously, knowing whether the firm is proprietary or nonprofit. and knowing the entrepreneur's initial contribution, $d_{0}$. In a subgame-perfect equilibrium, everyone also anticipates that the entrepreneur will contribute optimally in the last stage.

Suppose first that the entrepreneur has chosen to found a proprietary firm, and made an initial contribution of $d_{0}$. Contributors then realize that total contributions of $D_{-0}$ at this stage will result in total expenditures of

$$
d_{0}+D_{-0}+e^{p}\left(d_{0}, D_{-0}\right)=h_{0}\left(w_{0}+D_{-0}\right)
$$

towards production of the public good. Since $h_{0}(\cdot)$ increases at a rate less than one, then a dollar contributed by the public will result in a less than one dollar increase in expenditures to produce the public good.

Letting $D_{-0 i}=D_{-0}-d_{i}$, then individual contributions will be

$$
d_{i}^{p}=\arg \max _{d_{i} \in\left[0 . w_{i}\right]}\left\{u_{i}\left(u_{i}-d_{i}, h_{0}\left(w_{0}+D_{-0 i}^{p}+d_{i}\right)\right)\right\}, i=1.2, \ldots, n
$$

in a subgame perfect equilibrium. Sote that $d_{0}$ does not appear in (4). Since the entrepreneur remains free to take back any amount she previously contributed to her enterprise, this money is not 'committed' to be spent on the production of the public good, and other potential donors ignore it. Their equilibrium actions at this stage are therefore independent of the entrepreneur's initial contribution. In the two individual case illustrated in Figure 1, individual 1 is in the position of a Stackelberg leader. In determining his optimal contribution to the proprietary firm, he anticipates that the entrepreneur will bring the final level of provi- 
sion to $h_{0}\left(w_{0}+d_{1}\right)$ and therefore contributes $d_{1}^{p}$. leaving her to adjust her final contribution so as to obtain vector $P$ where his indifference curve is tangent to her reaction function. ${ }^{11}$

If instead the entrepreneur had founded a nonprofit firm. public contributors can calculate that total donations of $D_{-0}$ will result in equilibrium expenditures of

$$
d_{0}+D_{-0}+e^{n}\left(d_{0}, D_{-0}\right)=\max \left\{d_{0}+D_{-0}, h_{0}\left(w_{0}+D_{-0}\right)\right\}
$$

toward production of the public good. Individual contributions at this stage will then be

$$
\delta_{i}\left(d_{0}\right)=\arg \max _{d_{i} \in\left[0, w_{i}\right]}\left\{u_{i}\left(u_{i}-d_{i}, d_{0}+d_{i}+\sum_{j \neq i} \delta_{j}\left(d_{0}\right)+e^{n}\left(d_{0}, d_{i}+\sum_{j \neq i} \delta_{j}\left(d_{0}\right)\right)\right)\right\}
$$

in a subgame perfect equilibrium.

The level of individual contributions will depend on whether individual contributors anticipate that the non-distribution constraint will be binding on the entrepreneur or not. If $d_{0}+D_{-0}<h_{0}\left(w_{0}+D_{-0}\right)$, the non-distribution constraint is not binding, so that $i$ expects the entrepreneur to contribute again. In this case, individual $i$ is in the position of a Stackelberg leader and anticipates that each additional dollar contributed to the firm will induce the entrepreneur to reduce her final contribution by a fraction of a dollar. Individual equilibrium contributions are then identical to (4). Intuitively, the imposition of a non-distribution constraint cannot have any impact on equilibrium behavior if it is not binding. When the non-distribution constraint is binding on the entrepreneur, then $e^{n}\left(d_{0}, d_{i}+\sum_{j \neq i} \delta_{j}\left(d_{0}\right)\right)=0$ and individual $i$ is in the position of a Stackelberg follower. Then, an additional dollar contributed to the firm increases the expenditures dedicated to the public good's production by a dollar.

11

Varian(1994) presents a complete analysis of such a Stackelberg model. 
When the firm is nonprofit, equilibrium contributions generally depend on $d_{0}$ because a larger $d_{0}$ increases the funds earmarked for the public good's production and decreases the entrepreneur's available wealth. This. in turn. reduces the level of public donations that is necessary to cause the non-distribution constraint to bind. For any value of $d_{0}$ there is a level of contributions, $\bar{D}\left(d_{0}\right)$, which makes the non-distribution constraint just binding on the entrepreneur ${ }^{12}$. Note that $\bar{D}\left(d_{0}\right)$ is decreasing in $d_{0}$ because the more money the entrepreneur commits to the enterprise initially, the less wealth she has left at the last stage, and hence the smaller the level of total contributions required to induce her to contribute no further.

In the two individuals case, the typical decision problem facing individual 1 is illustrated in Figure 2. Contributing any $d_{1}$ such that $d_{1}+d_{0}<\bar{D}\left(d_{0}\right)$ leaves the entrepreneur wanting to contribute again and therefore reducing her contribution at the rate implicit in $h_{0}($.$) for$ each dollar he contributes. On the other hand, a contribution greater than this makes the non-distribution constraint binding on the entrepreneur, so that each dollar contributed increases $D$ by one dollar. For any $d_{0}$, his choice set is bounded by the outermost of the two curves, $D=h_{0}\left(w_{0}+w_{1}-x_{1}\right)$ and $D=d_{0}+w_{1}-x_{1}$, and this second curve depends on $d_{0}$. For example, if the entrepreneur's initial contribution is $d_{0}^{a}$, individual 1 chooses $d_{1}^{p}$ such that $d_{0}^{a}+d_{1}^{p}<\bar{D}\left(d_{0}^{a}\right)$, and the entrepreneur contributes again in the last stage so that $D^{p}$ is provided in total. On the other hand, an initial contribution of $d_{0}^{b}>d_{0}^{a}$ induces him to contribute $d_{1}^{b}>d_{1}^{p}$. Interestingly, by increasing her initial contribution sufficiently, the entrepreneur can induce the other to contribute more. This happens because when the 12

Formally, $\bar{D}\left(d_{0}\right)=\max \left\{D \mid h_{0}\left(w_{0}+D-d_{0}\right) \geq D\right\}$, so that $h_{0}\left(w_{0}-d_{0}+\bar{D}\left(d_{0}\right)\right) \equiv \bar{D}\left(d_{0}\right)$ 


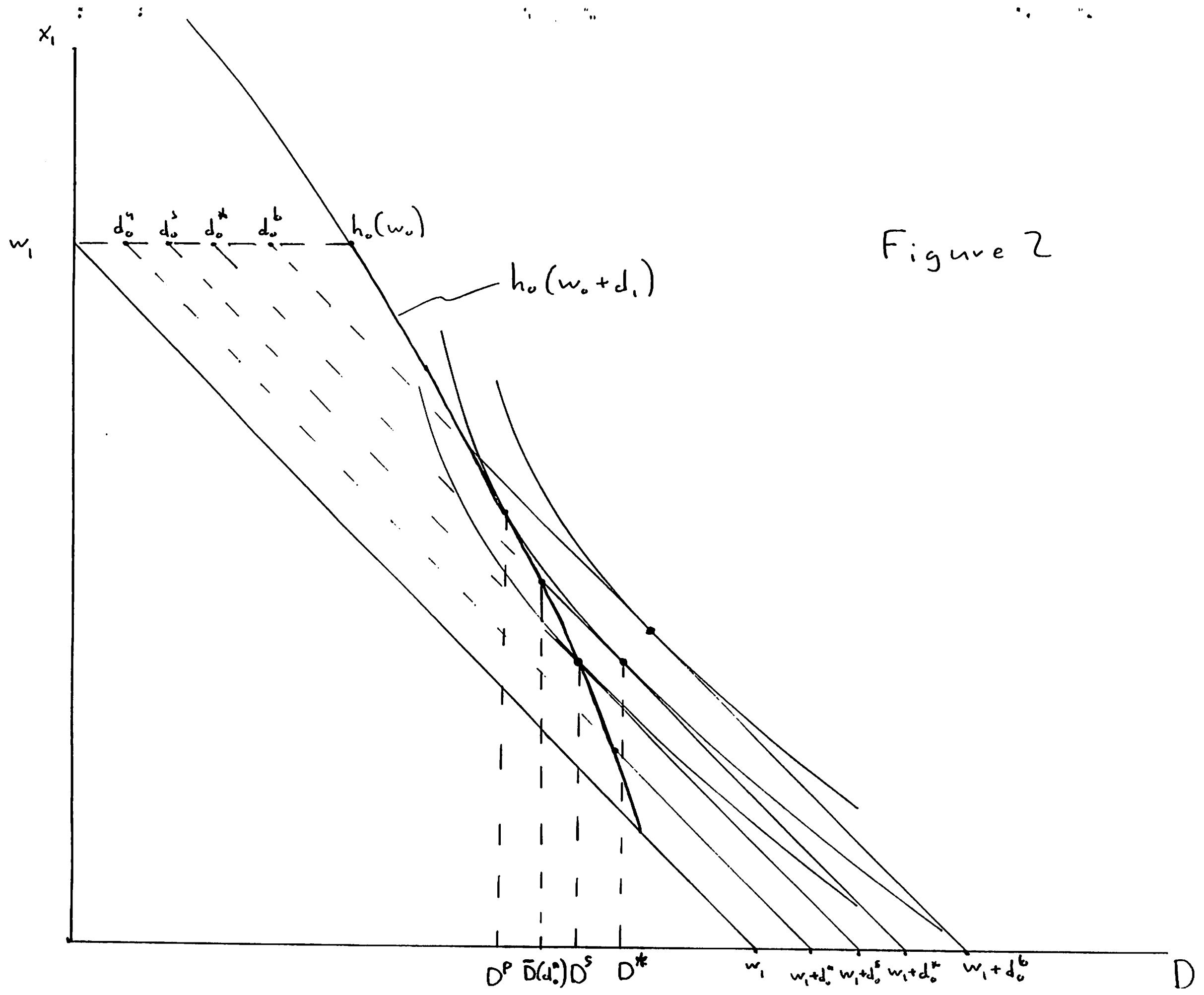


enterprise is nonprofit, a bigger initial contribution decreases the threshold at which the non-distribution constraint becomes binding. This makes it easier for the entrepreneur to convince the public that she does not intend to contribute again and forces the public to take responsibility for the final level of provision (i.e., to play as Stackelberg followers).

The essential point here is that the only effect a variation in $d_{0}$ has on the continuation of the game is that it changes the location of the 'kink' in the other individual's choice set. Note also that the segment of $\# 1$ 's choice set given by $D=h_{0}\left(w_{0}+w_{1}-x_{1}\right)$ is a subset of the one he faces in the proprietary subgame. so a small enough initial contribution by the entrepreneur would be followed by $d_{1}^{p}$. It follows that there is a unique $d_{0}^{*}$, which, if contributed by the entrepreneur initially, leaves the other individual indifferent between contributing $d_{1}^{p}$ or a larger amount $d_{1}^{*}$ which is just sufficient to make the non-distribution constraint exactly binding on the entrepreneur.

In Figure 1, if the firm is nonprofit. \#1's reaction function is made up of two segments. If $d_{0} \leq d_{0}^{*}, \# 1$ cannot do better than contributing $d_{1}^{p}$, in which case the non-distribution constraint would not be binding, and the equilibrium continuation again would yield an outcome at $P$, with individual 1 on indifference curve $u_{1}$, just as if the firm had been proprietary. But if $d_{0} \geq d_{0}^{*}$, then \#1's best response is to choose his own contribution along locus $d_{1}=h_{1}\left(w_{1}+d_{0}\right)-d_{0}$, since the NDC would then be binding. If the entrepreneur contributes exactly $d_{0}^{*}$ initially, the other individual will be indifferent between contributing $d_{1}^{p}$ (and letting the entrepreneur contribute again to obtain the outcome at $P$ ) or contributing $d_{1}^{*}$ (and obtaining the outcome at $N$ ). 


\subsection{Contributing once is enough}

In stage 3. the entrepreneur chooses an initial contribution level. However. the logic of her equilibrium choice is not transparent when there are many other contributors. We will therefore only discuss the $n=1$ case here. The case of $n>1$ identical contributors is presented in the Appendix. The results for the many contributors case are qualitatively similar.

In Figure 1. if the entrepreneur has chosen to found a proprietary firm, then she cannot avoid being in the position of a Stackelberg follower. and the final outcome nill be at point $P$. Individual 1 anticipates that the entrepreneur will adjust her final contribution such that, for any initial $d_{0}$, and any contribution by him of $d_{1}$, total donations satisfy $d_{0}+e_{0}=$ $h_{0}\left(w_{0}+d_{1}\right)-d_{1}$, and so chooses $d_{1}^{p}$. If $h_{0}($.$) is increasing and concave as assumed. then$ $d_{1}^{p}$ is unique. So in the unique equilibrium outcome, the entrepreneur contributes any $d_{0}$ initially, the other individual contributes $d_{\mathfrak{L}}^{p}$, and the entrepreneur makes up the difference (positively or negatively) in the last stage to attain a level $D^{p}$ of total donations. Therefore $d_{1}^{p}$ is independent of $d_{0}$, and the entrepreneur always contributes $d_{0}^{p}$ in total.

Note that if the entrepreneur derived no utility from the public good. $h_{0}(.) \equiv 0$, and individual contributors would expect her to appropriate every dollar they contribute for her own private consumption, and so would also contribute nothing. However. individuals may be willing to contribute voluntarily even to a proprietary firm $\left(d_{1}^{p}>0\right)$, provided its founder/manager cares enough about the public good aspect of what the firm provides to allocate part of any donations received to it. In such a case, they effectively face a price for the public good that is inversely related to the entrepreneur's income elasticity of demand 
for $Z$.

If the enterprise is nonprofit. the unique subgame perfect equilibrium is at $N$ in Fig:sre 1, where the entrepreneur contributes $d_{0}^{*}$ initially and the other responds by contributing $d_{1}^{*}$. The entrepreneur gives no less than $d_{0}^{*}$ because this would result in a discontinuous decrease in the contribution of the other individual to $d_{1}^{p}$ which would force her to contribute again: up to $d_{0}^{p}$ in total. The outcome would be at $P$, and she would be on indifference curve $u_{0}<u_{1}$. Thus any $d_{0}<d_{0}^{*}$ would result in a larger outlay by the entrepreneur, but less total contributions than if she contributes $d_{0}^{*}$. On the other hand. any larger $d_{0}$ causes $d_{1}$ to fall in response at a less than one for one rate and yields an outcome on \#1's reaction function to the north-west of point $N$, and this is also strictly worse for her. In equilibrium then, the entrepreneur makes an initial donation which is just large enough that she would not want to contribute again after the other has contributed optimally in response. As for individual 1 , even though he is indifferent between contributing $d_{1}^{p}$ and $d_{1}^{*}$, only $d_{1}^{*}$ is an equilibrium response to $d_{0}^{*}$ because if he contributed $d_{1}^{p}$ the entrepreneur would be better off contributing $d_{0}^{*}+\varepsilon$ initially.

\subsection{To profit or not to profit?}

So far we have found that if the firm is nonprofit, the equilibrium would be at point $N$ in Figure 1, where the entrepreneur contributes $d_{0}^{*}$ and total contributions are $D^{*}$, while if the firm is proprietary, the equilibrium would be at point $P$, where she contributes $d_{0}^{p}$ and total contributions are $D^{p}$. Which will she prefer? The answer is immediate from Figure 1: $d_{0}^{*}<d_{0}^{p}$ while $D^{*}>D^{p} .^{13}$ The entrepreneur gets to consume more public good while 13 
contributing less to its provision winen the firm is nonprofit.

So an entrepreneur who wants to produce a public good will always find it in her interest to found a nonprofit firm ${ }^{14}$. The non-distribution constraint provides the entrepreneur with a means of committing to not appropriate funds which others wish to assign to the provision of the public good. and so it induces higher donations by the public. Imposing a perfectly enforced non-distribution constraint on herself is in the entrepreneur's interest because it allows her to contribute less and consume more of the public good than if she were not subject to this constraint.

An essential aspect of this model is that the firm provides a non-excludable and nonrival good. If no one but the entrepreneur derived utility from jointly consuming the firm's output, then no one else would be willing to contribute to its provision, whether the firm was proprietary or not. In that case, there would be no advantage to the entrepreneur from founding a nonprofit firm either. And if the good in question is easily excludable, customers would demand (and the entrepreneur would have to provide them with) an immediate quid pro quo for their money - access to consuming the good. So for example. while the organizers of an outdoor street concert may have to rely on voluntary contributions. a firm would sell admission tickets for an indoor concert, which is easily excludable, instead of relying on voluntary donations ${ }^{15}$.

The total level of contributions at $N$ and $P$ can be seen by drawing a line with slope -1 from these points to either axis. These lines have been omitted to avoid cluttering the diagram. 14

A sufficient condition for this result to hold is that $d_{0}^{s}>0$, as assumed. This means that the entrepreneur herself gets some utility from the firm's output and has sufficient income that she would contribute positively toward its provision. If this is not the case, she may contribute nothing whether the firm is proprietary or not, and so would have no reason to prefer a nonprofit firm. 15

Note that this does not imply that theaters and orchestras performing indoors could not also solicit and receive voluntary donations. Some nonprofit firms, e.g., hospitals, theater groups or philharmonic orchestra, receive revenues from the sale of excludable goods and user fees, while at the same time receiving donations 
When there are just two individuals contributing positively, the public donor is indifferent as to whether the public good producing firm is proprietary or nonprofit. However. since the entrepreneur is strictly better off with a nonprofit firm, nonprofit institutions Paretodominate proprietary firms when it comes to producing public goods. This rare opportunity to make possible actual Pareto improvements could explain why governments have enacted legislation allowing the incorporation of nonprofit organizations and provided the institutional mechanisms for the enforcement of the non-distribution constraint on the net cash flows of nonprofit enterprises. ${ }^{16}$ However. possible welfare gains need not be relevant to the entrepreneur's decision. If she would be a positive contributor and expects any contributions from the other, a rational self-interested entrepreneur will always choose to incorporate her public good producing organization under nonprofit regulations, not because this is socially optimal in some sense, but because it is in her best interest to do so.

\subsection{Why me?}

So far, we have found that in any subgame perfect equilibrium, the entrepreneur would found a nonprofit firm. She will also invest sufficiently in it that the non-distribution constraint will be binding on her. The last question that remains to be answered is whether it can be in anyone's interest to be a nonprofit entrepreneur.

to ensure their continued existence. Such firms could be viewed formally as producing two goods: a private good sold to consumers(e.g., medical care, a concert, a play) and a public good (the option value of their existence) to which individuals may contribute voluntarily. The model in this paper assumes that the firm produces only a single public good. Bilodeau and Slivinski(1995d) extend the present model to potentially profitable multiproduct irms producing both a public and a private good.

This is not a rationale for tax exemption of nonprofit organizations, nor for the tax-deductibility of contributions made to them however. See Hall(1987) for an historical overview of the evolution of legislation governing the nonprofit sector in the U.S.A. Note also that the equilibrium outcome still falls short of Paretoefficiency, so nonprofit enterprises are not a solution to the free rider problem. The non-distribution constraint is only an efficient institutional means of overcoming the particular agency problem arising when donors cannot receive an immediate quid pro quo for their gifts. 
An important factor affecting individuals: decisions to volunteer or not to perform this task is the fact that not only will the entrepreneur not profit from this venture, but there is a cost to being the entrepreneur. To see this. consider Figure 1 again. In equilibrium, the entrepreneur contributes $d_{0}^{*}>d_{0}^{s}$ while the other individual contributes $d_{1}^{*}<d_{1}^{s}$. But if the roles were reversed, it is individual 0 who would contribute less than $d_{0}^{s}$ while individual 1 as entrepreneur would contribute more than $d_{1}^{9}$. The individual who volunteers must therefore always contribute more than she would if someone else organized the public good's production. Everyone would therefore prefer to let someone else be the provider of nonprofit entrepreneurial services.

While it is true that both would prefer to let the other volunteer nonprofit entrepreneurial services, this does not mean that no one will do so. On the contrary, anyone can reason that if no one volunteers, the public good will not be provided at all. Any individual who does 'volunteer' to be the entrepreneur will be better off with her resulting consumption bundle than with $\left(w_{i}, 0\right)$, because as the entrepreneur she has available the strategy of choosing $d_{i}=e_{i}=0$. So if no one else volunteers, $i$ would rather incur the cost of entrepreneurship than consume no public good at all. If we also assume that if two or more individuals volunteer simultaneously, they both have to incur at least a part of the entrepreneurship cost, then the game at the first stage is simply a game of chicken. In any pure strategy equilibrium, one and only one individual will volunteer nonprofit entrepreneurial services. Therefore, even though there is a cost to doing so, it is consistent with an individual's selfinterest to volunteer nonprofit entrepreneurial services. Of course, as in any game of chicken, there are equilibria in which any one individual is the volunteer. Predictions regarding 
the traits of those individuals in a heterogeneous population who will volunteer nonprofit entrepreneurial services are generared in Bilodeau and Slivinski(1995b). ${ }^{17}$.

\section{Conclusion}

This paper has provided a simple rationale for the existence of nonprofit firms: to provide nonexcludable public goods. In any instance in which the production of such a good is financed by voluntary contributions. it is in both the private interest of the entrepreneur and in the wider public interest that the firm which produces the good be nonprofit.

17

Other relevant papers on this topic are Bliss and Nalebuff (1984), Bilodeau and Slivinski(1995a) and Eckel and Steinberg(1993). In the simple model presented here, only one individual founds a nonprofit firm, so the possibility of competing charities does not arise. A model of rival charities competing for donations is presented in Bilodeau and Slivinski(1995c). 


\section{A Appendix: Many contributors}

When there are more than one potential contributors, analysis of the model becomes considerably more complicated. In particular. the equilibrium continuation in the 'nonprofit' subgame is not unique. We simplify matters in this paper by assuming that all individuals have the same preferences. ${ }^{18}$

Consider first the subgame which follows a choice by the entrepreneur to found a proprietary enterprise. It is still true that her final contribution is determined by (2). Then it follows that if $h_{0}()$ is concave. and $x_{j}$ and $D$ are normal goods for each $j$ with respect to the derived utility function $u_{j}\left(x_{j}, h_{0}\left(w_{0}+D\right)\right)$, then there is again a unique equilibrium set of contributions $d^{p}=\left(d_{0}^{p}, d_{1}^{p}, \ldots, d_{n}^{p}\right)$ Further, it is also the case that $D^{p}<D^{s}$, that $D_{-0}^{p}<D_{-0}^{s}$, and $d_{0}^{p}>d_{0}^{s}$. Thus, the choice of a proprietary institutional form will again result in the entrepreneur contributing more than she would in a simultaneous contributions game. with others contributing less in aggregate.

As to the nonprofit sub-game. it is characterized by the following facts:

Fact 1 If the entrepreneur initially contributes the amount $d_{0}^{s}$, then it is not an equilibrium response for the public to contribute the amounts $\left[d_{j}^{s}\right]$. Similarly, they cannot respond in equilibrium to an initial contribution of $d_{0}^{p}$ by contributing $\left[d_{i}^{p}\right]$.

The intuition behind Fact 1 is identical to that which arose with a single contributor. Because $d_{0}^{s}$ would be the entrepreneur's best-response to $D_{-0}^{s}$ in a simultaneous contributions game, just as $d_{0}^{p}$ would be to $D_{-0}^{p}$, these cannot occur in a game in which the entrepreneur has an opportunity to make a final contribution. In the first case, if the $n$ general contributors were to contribute $d_{j}^{s}$ in response to $d_{0}^{s}$, every public contributor for whom $d_{j}^{s}>0$ would have an incentive to deviate to a 18

All we need for the results in this section is that all individuals other than the entrepreneur have identical preferences, and even that is not necessary for all of our results. 
lower contribution level. so as to cause the entrepreneur to contribute more later. Similarly, a general response of $d_{j}^{p}$ to $d_{0}^{p}$ would leave every general contributor for whom $d_{j}^{p}>0$ with an incentive to deviate to a contribution which is large enough to induce the entrepreneur to give no more than the initial $d_{0}^{p}$ at the last stage.

Fact 2 There exist critical values of initial contributions in the non-profit sub-game, denoted as $d_{0}^{l}$, and $d_{0}^{u}$, such that:

(i) A contribution of $d_{j}^{p}$ for each contributor $j$ is an equilibrium response to $d_{0}$ if and only if $d_{0} \leq d_{0}^{u}$, and

(ii) A contribution of $\delta_{j}^{n}\left(d_{0}\right)$ for each $j$ is an equilibrium response to $d_{0}$ if and only if $d_{0} \geq d_{0}^{l}$.

Here, $\delta_{j}^{n}($.$) refers to the unique subgame perfect equilibrium response of individual j$ in the last stage of a game in which the entrepreneur makes an initial contribution $d_{0}$, followed by simultaneous contributions by all others, at which point the game ends, and the entire sum of the $n+1$ contributions is turned into the public good.

Fact 2 expresses the idea that if the entrepreneur initially gives a sufficiently small amount, the unique equilibrium response of all public contributors is to take advantage of the fact that he cannot commit to not contribute again after they have. so they respond with contributions of $d_{j}^{p}$-just as if the entrepreneur had founded a proprietary firm. Then. $d_{0}^{u}$ is the upper bound on initial contributions which necessarily elicit this equilibrium response. If the entrepreneur contributes any amount greater than $d_{0}^{u}$ initially, some other contributor $j$ will have an incentive to deviate from contributing $d_{j}^{p}$ - by contributing more-when all $k \neq j$ contribute $d_{k}^{p}$. On the other hand, the entrepreneur can commit to give no more by making a sufficiently large initial contribution, so that other contributors must respond in equilibrium as though he will not-that is, they respond as if the game had no final stage in which the entrepreneur can contribute further. On the other hand, $d_{0}^{l}$ is the lower bound on $d_{0}$ values which necessarily elicit this equilibrium response from contributors. Any initial entrepreneurial 
contribution less than $d_{0}^{l}$ will leave some $j$ with a positive incentive to contribute less than $\delta_{j}^{n}\left(d_{0}\right)$ when all $k \neq j$ contribute $o_{k}^{n}\left(d_{0}\right)$.

To define the critical values of $d_{0}$, we need some notation and definitions. First, consider a two-stage game in which the entrepreneur contributes some $d_{0}$. after which the others contribute simultaneously, and the game then ends. For any $d_{0}$ then. there is a unique vector of subgame perfect equilibrium responses, $\left[\delta_{j}^{n}\left(d_{0}\right)\right]$, using Theorem 3 of Bergstrom, Blume and Varian (1986). Let $\Delta^{n}\left(d_{0}\right)=\sum_{j=1}^{n} \delta_{j}^{n}\left(d_{0}\right)+d_{0}$ and $\Delta_{-j}^{n}()=.\sum_{i \neq j} \delta_{i}^{n}\left(d_{0}\right)+d_{0}$, and let $\Delta_{-0}^{n}\left(d_{0}\right)=\Delta^{n}\left(d_{0}\right)-d_{0}$, and $x_{j}^{n}\left(d_{0}\right)=w_{j}-\delta_{j}^{n}\left(d_{0}\right)$.

Now, for any $d_{0} . j \neq 0$ and $D_{-0 j}$, let

$$
k_{j}\left(d_{0}, D_{-0 j}\right)=\max \left\{0, \bar{D}\left(d_{0}\right)-D_{-0 j}-d_{0}\right\}
$$

and

$$
K_{j}\left(d_{0}, D_{-0 j}\right)=\min \left\{w_{j}, K_{j}\left(d_{0}, D_{-0 j}\right)\right\}
$$

When $\left.k_{j}(.) \in\right] 0, w_{j}\left[\right.$, this is the level of $d_{j}$ at which the 'kink' occurs in the boundary of $j$ 's choice set.

Now let $U_{j}^{n}\left(d_{0}\right)=u_{j}\left(w_{j}-\delta_{j}^{n}\left(d_{0}\right), d_{0}+\Delta^{n}\left(d_{0}\right)\right)$ and $U_{j}^{p}=u_{j}\left(w_{j}-d_{j}^{p}, D^{p}\right)$ be $j$ s payoffs in the "nonprofit' and 'proprietary' equilibrium respectively. Note that since $x_{j}^{n}($.$) is increasing when it is$ less than $w_{j}$, and $\Delta^{n}($.$) is increasing, then U_{j}^{n}($.$) is increasing with d_{0}$. Let

$$
A_{j}^{n}\left(d_{0}\right)=\max _{d_{j}}\left\{u_{j}\left(w_{j}-d_{j} . h_{0}\left(u_{0}+\Delta_{-0 j}^{n}\left(d_{0}\right)+d_{j}\right) \mid 0 \leq d_{j} \leq K_{j}\left(d_{0} . \Delta_{-0 j}^{n}\left(d_{0}\right)\right)\right\}\right.
$$

be $j$ s payoff if he 'deviates down from a contribution of $\delta_{j}^{n}\left(d_{0}\right)$ when all $k \neq j$ are contributing $\delta_{k}^{n}\left(d_{0}\right)$, after the entrepreneur has contributed $d_{0}$. Similarly, let

$$
A_{j}^{p}\left(d_{0}\right)=\max _{d_{j}}\left\{u_{j}\left(w_{j}-d_{j}, D_{-0 j}^{p}+d_{0}+d_{j}\right) \mid K_{j}\left(d_{0}, D_{-0 j}^{p}\right) \leq d_{j} \leq w_{j}\right\}
$$

be $j$ 's payoff if he 'deviates up' from a contribution of $d_{j}^{p}$ when all others are contributing $d_{j}^{p}$ after the entrepreneur has contributed $d_{0}$.

Note that if $K_{j}\left(d_{0}, \Delta_{-0 j}^{n}\left(d_{0}\right)\right)=0$, then it must be that $h_{0}\left(u_{0}+\Delta_{-0 j}^{n}\left(d_{0}\right)\right)<\Delta_{-j}^{n}\left(d_{0}\right)$, so that $A_{j}^{n}\left(d_{0}\right)=u_{j}\left(w_{j}, h_{0}\left(w_{0}+\Delta_{-0 j}^{n}\left(d_{0}\right)\right)\right)<u_{j}\left(w_{j}, \Delta_{-j}^{n}\left(d_{0}\right)\right) \leq U_{j}^{n}\left(d_{0}\right)$. Also, if $K_{j}\left(d_{0}, \Delta_{-0 j}^{n}\left(d_{0}\right)\right)=w_{j}$, then $h_{0}\left(w_{0}+\Delta_{-0 j}^{n}\left(d_{0}\right)+d_{j}\right)>\Delta_{-j}^{n}\left(d_{0}\right)+d_{j}$, for any $d_{j} \in\left[0, w_{j}\right]$, so $A_{j}^{n}\left(d_{0}\right)>U_{j}^{n}\left(d_{0}\right)$. 
Similarly, if $K_{j}\left(d_{0} . D_{-0 j}^{p}\right)=0$. then $D_{-0 j}^{p}+d_{0}+d_{j}^{p}>h_{0}\left(w_{0}-D_{-0}^{p}\right)=D^{p}$. and so $A_{j}^{p}\left(d_{0}\right)>U_{j}^{p}$. Also. if $K_{j}\left(d_{0}, D_{-0 j}^{p}\right)=w_{j}$, then for any $d_{j} \in\left[0 . w_{j}\right]$ we have that $h_{0}\left(w_{0}+D_{-0 j}^{p}+d_{j}\right)>D_{-0 j}^{p}+d_{0}+d_{j}$, so that $U_{j}^{p} \geq u_{j}\left(w_{j}-d_{j}, h_{0}\left(w_{0}+D_{-0 j}^{p}+d_{j}\right)\right)>u_{j}\left(w_{j}-d_{j}, D_{-0_{j}}^{p}-d_{j}\right)$, and therefore. $U_{j}^{p}>A_{j}^{p}\left(d_{0}\right)$.

Since $\bar{D}($.$) is decreasing in d_{0}, K_{j}($.$) is non-increasing in both it's arguments. Since \Delta_{-j}^{n}\left(d_{0}\right)$ is increasing in $d_{0}$, then $\bar{D}\left(d_{0}\right)-\Delta_{-j}^{n}\left(d_{0}\right)$ is also decreasing in $d_{0}$. and thus $K_{j}\left(d_{0}, \Delta_{-0 j}^{n}\left(d_{0}\right)\right)$ is nonincreasing in $d_{0}$. This then implies that $A_{j}^{p}\left(d_{0}\right)$ is continuous and non-decreasing in $d_{0}$, while $U_{j}^{n}\left(d_{0}\right)$ is increasing and continuous in $d_{0}$, and $A_{j}^{n}\left(d_{0}\right)$ is continuous and non-increasing in $d_{0}$.

Now let

$$
\Omega^{n}\left(d_{0}\right)=\max _{j}\left\{A_{j}^{n}\left(d_{0}\right)-U_{j}^{n}\left(d_{0}\right)\right\},
$$

be the gain of the individual who can gain the most from 'deviating down'. This must be nonincreasing in $d_{0}$. We have already that if $D_{-0}^{s}>0$. then $\Omega^{n}\left(d_{0}^{s}\right)>0$. Further, since $K_{j}\left(w_{0}, \Delta_{-0 j}^{n}\left(w_{0}\right)\right)=$ 0 , for all $j$, then $A_{j}^{n}\left(w_{0}\right)<U_{j}^{n}\left(d_{0}\right)$ for all $j$, so that $\Omega^{n}\left(w_{0}\right)<0$. Therefore we can uniquely define

$$
d_{0}^{l} \equiv \min \left\{d_{0} \mid \Omega^{n}\left(d_{0}\right) \leq 0\right\}
$$

This is the unique smallest $d_{0}$ for which no contributor wants to unilaterally 'deviate down', and is greater than $d_{0}^{s}$, and less than $w_{0}$. Now define

$$
\Omega^{p}\left(d_{0}\right) \equiv \max _{j}\left\{A_{j}^{p}\left(d_{0}\right)-U_{j}^{p}\right\}
$$

which is non-decreasing in $d_{0}$ by similar arguments. We then define

$$
d_{0}^{u} \equiv \max \left\{d_{0} \mid \Omega^{p}\left(d_{0}\right) \leq 0\right\} .
$$

The two Facts then imply that $d_{0}^{s}<d_{0}^{l}$, and $d_{0}^{p}>d_{0}^{u}$, so that there are two broad cases to consider.

Case I: $d_{0}^{l} \leq d_{0}^{u}$.

In this case, the two critical initial contribution levels are bracketed by $d_{0}^{s}$ and $d_{0}^{p}$, and the only possible equilibrium outcomes are analogous to that of the single contributor case.

For any $d_{0}<d_{0}^{l}$, the only equilibrium response is $\left[d_{j}^{p}\right]$, while for any $d_{0}>d_{0}^{z}$, only $\left[\delta_{j}^{n}\left(d_{0}\right)\right]$ can be an equilibrium response by the other contributors. For $d_{0}$ values between these two critical values, both $\left[d_{j}^{p}\right]$ and $\left[\delta_{j}^{n}\left(d_{0}\right)\right]$ are possible joint equilibrium responses by the general public.

To see how an equilibrium is constructed, note that if the entrepreneur chooses any $d_{0}$ which is responded to with $d_{j}^{p}$ by all contributors, he must end up contributing $d_{0}^{p}$ in total, with $D^{p}$ being 
the resulting total contributions. Any $d_{0}$ which elicits $\delta_{j}^{n}\left(d_{0}\right)$ as a response for all $j$, yields total contributions of $\Delta^{n}\left(d_{0}\right)$, with the entrepreneur contributing no more than the initial $d_{0}$. Further, if $d_{0}>d_{0}^{s}$, the entrepreneur's utility, $u_{0}\left(w_{0}-d_{0}, \Delta^{n}\left(d_{0}\right)\right)$, is decreasing in $d_{0}$.

Now, with the responses of the contributors to $d_{0}$ values between $d_{0}^{l}$ and $d_{0}^{u}$ being either of these two possibilities. the entrepreneur's unique equilibrium strategy must be to choose the smallest value in that interval which elicits a response of $\delta_{j}^{n}\left(d_{0}\right)$. The only requirement on the contributors' strategies then is that there must exist such a minimum value. By choosing appropriately the public contributors' strategies for $d_{0}$ values in the interval $\left[d_{0}^{l}, d_{0}^{u}\right]$, any $d_{0}$ in this interval can be the entrepreneur's equilibrium choice, which we henceforth denote as $d_{0}^{*}$. These findings are summarized in the following proposition.

Proposition 1 If $d_{0}^{l}<d_{0}^{u}, d_{i}^{s}>0 \quad \forall i$, and both the public good and private consumption are normal, then for any $n$ every equilibrium outcome has the following properties:

(i) The entrepreneur chooses to found a non-profit firm, and chooses an initial contribution $d_{0}^{*}$ from the interval $\left[d_{0}^{l}, d_{0}^{u}\right]$, which is therefore greater than $d_{0}^{s}$, but less than $d_{0}^{p}$. Formally, $d_{0}^{*}=$ $\min \left\{d_{0} \mid \forall j, \delta_{j}\left(d_{0}\right)=\delta_{j}^{n}\left(d_{0}\right)\right\}$.

(ii) Other contributors all respond by contributing the amounts $\delta_{j}^{n}\left(d_{0}^{*}\right)$, resulting in total contributions of $\Delta^{n}\left(d_{0}\right)$.

(iii) The entrepreneur contributes nothing further, so that the level of total contributions remains $\Delta^{n}\left(d_{0}^{*}\right)$, which is more than both $D^{s}$ and $D^{p}$. Further, any level of $d_{0} \in\left[d_{0}^{l}, d_{0}^{u}\right]$ can be an equilibrium choice by the entrepreneur, for an appropriate choice of the $n$ general contributors' strategies.

This implies that the entrepreneur's equilibrium initial (and therefore total) contribution is more than $d_{0}^{s}$, and less than he would contribute were he to found a proprietary firm $\left(d_{0}^{p}\right)$. Further, since the functions $\delta_{j}^{n}($.$) are non-increasing, the general public in aggregate give less than D_{-0}^{s}$ but more than $D_{-0}^{p}$, with total donations (including that of the entrepreneur) nonetheless being greater than $D^{s}$, and therefore also greater than $D^{p}$. This is why the entrepreneur will never choose to found a proprietary firm when the non-profit subgame is characterized as in Case I: founding a nonprofit results in a smaller personal contribution, but a larger level of total donations. 
Case II: $d_{0}^{u}<d_{n}^{l}$

The definitions of these critical values imply that in this case. there can be no subgame perfect equilibrium in which only pure strategies are employed. The oniy possible pure strategy responses to any $d_{0}$ are $\left[d_{j}^{p}\right]$ or $\left[\delta_{j}^{n}\left(d_{0}\right)\right]$, and neither of these can be an equilibrium response for initial contributions by the entrepreneur which fall between $d_{0}^{u}$ and $d_{0}^{l}$. This is because someone would have an incentive to deviate from either of these strategy profiles when the initial contribution by the entrepreneur is in this range. It may be that there are equilibrium continuation strategies for these $d_{0}$ values in which the contributors randomize over their contributions. but determining the structure of an equilibrium with mixed strategies is problematic in a model with non-linear payoff functions. So we have not characterized the equilibria for this case.

Note however that as long as $d_{0}^{l}<d_{0}^{p}$, choosing a nonprofit firm and then contributing $d_{0}^{l}$ will always be a strategy that is available to the entrepreneur, and which results in the outcome $d_{0}^{l}, \Delta^{n}\left(d_{0}^{l}\right)$, which dominates the proprietary outcome $d_{0}^{p}, D^{p}$ for the entrepreneur, since $\Delta^{n}\left(d_{0}^{l}\right)>\Delta^{n}\left(d_{0}^{s}\right)=D^{s}>$ $D^{p}$. The following result is therefore of interest:

Proposition 2 If preferences are identical. then $d_{0}^{l}<d_{0}^{p}$, and $d_{0}^{u}>d_{0}^{s}$.

Proposition 2 implies that if an equilibrium exists under case II. and preferences are identical, then the entrepreneur will still never choose the proprietary institutional form, as the option of choosing a nonprofit firm. and contributing $d_{0}^{l}$ is preferable. The significance of the result that $d_{0}^{\mu}>d_{0}^{s}$ is only that there is a range of positive levels of contribution which will result in the 'proprietary outcome: even if $d_{0}^{l}<d_{0}^{l}$.

Since we have only characterized the equilibria for Case I, the following proposition is presented as assurance that we are not investigating the properties of a non-existent equilibrium. 
Proposition 3 If $x_{j}$ and $Z$ are both normal. $d_{0}^{s}$ and $D_{-0}^{s}$ are positive. $w_{j}=w$ for all $j$, and individuals have identical. affinely homothetic preferences ${ }^{19}$ then $d_{0}^{l} \leq d_{0}^{u}$.

Before proving propositions 1-3, we start with some preliminary lemmas. Throughout these proofs. the assumption that $d_{0}^{s}>0 . D_{-0}^{s}>0$, and that $x_{j}$ and $Z$ are normal is maintained.

Lemma $4 d^{p}$ is unique.

Proof. In the proprietary subgame. the $n$ contributors payoff functions are:

$$
u_{j}\left(w_{j}-d_{j}, h_{0}\left(w_{0}+D_{-0}\right)\right) \equiv v_{j}\left(w_{j}-d_{j}, D_{-0}\right),
$$

so we can define $g_{j}(y) \equiv \arg \max _{D_{-0}}\left\{v_{j}\left(y-D_{-0}, D_{-0}\right) \mid y \in[0, y]\right\}$, and we now have a simultaneous contributions game with utility functions $v_{j}($.$) . If h_{0}($.$) is concave, then the v_{j}($.$) are continuous, and$ strictly quasi-concave in $d_{j}$, and a Nash equilibrium will exist. If $x_{j}$ and $D_{-0}$ are both normal in $v_{j}($.$) , then Theorem 3$ of Bergstrom, et. al.(1986) applies to guarantee uniqueness of $d_{1}^{p}, \ldots, d_{n}^{p}$, and the uniqueness of $d_{0}^{p}$ is immediate.

Lemma $5 d_{j}^{p} \geq g_{j}\left(w_{j}+D_{-0 j}\right)-D_{-0 j}$, and if $d_{j}^{p}>0$, then $d_{j}^{p}<h_{j}\left(w_{j}+D_{-j}^{p}\right)-D_{-j}^{p}$.

Proof. The first claim follows immediately from standard arguments regarding simultaneous contributions games. The second claim is immediate because $h_{j}\left(w_{j}+D_{-j}^{p}\right)-D_{-j}^{p}$ is the amount $j$ would contribute for a given $D_{-j}^{p}$, if the entrepreneur gave the full amount $d_{0}^{p}$ initially and could not change this later. Thus, it is the amount he would give if his contributions went 'untaxed' by $h_{0}($.$) ,$ whereas $d_{j}^{p}$ is the amount given when taxed; in either case, a contribution of $d_{j}^{p}$ by $j$ results in $D^{p}$, so the result follows from a Slutsky substitution effect argument.

Lemma $6 D^{p}<D^{s}, d_{0}^{p}>d_{0}^{s}$, and $D_{-0}^{p}<D_{-0}^{s}$.

19

That is, individual preferences are an affine transformation of some homothetic preference ordering over $\left(x_{j}, D\right)$ pairs. See Blackorby, Boyce and Russell (1978). 
Proof. Suppose that $D^{p}>D^{s}$. b.w.o.c. Then $h_{0}\left(w_{0}+D_{-0}^{p}\right)=D^{p}>D^{s}=h_{0}\left(w_{0}+D_{-0}^{s}\right)$ so + it $h_{0}($.$) increasing implies D_{-0}^{p}>D_{-0}^{s}$, which in turn implies that some $j \neq 0$ has $d_{j}^{p}>d_{j}^{s}$. Howe er. $d_{j}^{p}>0$ then. so that $h_{j}\left(w_{j}+D_{-j}^{p}\right)-D_{-j}^{p}>d_{j}^{p}>d_{j}^{s} \geq h_{j}\left(w_{j}+D_{-j}^{s}\right)-D_{-j}^{s}$. So $D_{-j}^{p}<D_{-j}^{s}$, and therefore $D^{p}<h_{j}\left(w_{j}+D_{-j}^{p}\right)<h_{j}\left(w_{j}+D_{-j}^{s}\right) \leq D^{s}$. a contradiction.

Suppose now that $D^{p}=D^{s}$. Then again, $h_{0}\left(w_{0}+D_{-0}^{p}\right)=D^{p}=D^{s} \geq h_{0}\left(w_{0}+D_{-0}^{s}\right)$, so that $D_{-0}^{p} \geq D_{-0}^{s}$, and $d_{0}^{p} \leq d_{0}^{s}$. If $D_{-0}^{s}<D_{-0}^{p}$, we get a contradiction as above, so this leaves only the possibility that $D_{-0}^{s}=D_{-0}^{p}$, which implies $d_{0}^{s}=d_{0}^{p}$. If all $j \neq 0$ have $d_{j}^{p}=0$. then $D_{-0}^{p}=D_{-0}^{s}=0$. contrary to our assumption. and so some $d_{j}^{p}>0$. implying that for that $j, h_{j}\left(w_{j}+D_{-j}^{s}\right) \leq D^{s}=$ $D^{p}<h_{j}\left(w_{j}+D_{-j}^{p}\right)$, and therefore. $D_{-j}^{p}>D_{-j}^{s}$. Then for such a contributor, $j$, it follows that $d_{j}^{s} \geq h_{j}\left(w_{j}+D_{-j}^{s}\right)-D_{-j}^{s}>h_{j}\left(w_{j}+D_{-j}^{p}\right)-D_{-j}^{p}>d_{j}^{p}>0$.

Thus we have that if any $d_{j}^{p}>0$, then $d_{j}^{s}>d_{j}^{p}$, so that $D_{-0}^{s}>D_{-0}^{p}$, a contradiction. Hence $D^{p}<D^{s}$, so that $h_{0}\left(w_{0}+D_{-0}^{p}\right)=D^{p}<D^{s}=h_{0}\left(w_{0}+D_{-0}^{s}\right)$, so $D_{-0}^{p}<D_{-0}^{s}$, and thus $d_{0}^{p}=$ $h_{0}\left(w_{0}+D_{-0}^{p}\right)-D_{-0}^{p}>h_{0}\left(w_{0}+D_{-0}^{s}\right)-D_{-0}^{s}=d_{0}^{s}$

Establishing the properties of $d_{0}^{u}$ requires the identicality assumption. which is used explicitly in the following results. In particular. we simply note without proof. that with identical preferences. there exists $x^{p}$. and an increasing function $x^{n}\left(d_{0}\right)$, such that for every $j, d_{j}^{p}=\max \left\{0, u_{j}-x^{p}\right\}$, and $\delta_{j}^{n}\left(d_{0}\right)=\max \left\{0, w_{j}-x^{n}\left(d_{0}\right)\right\}$. Proofs are identical to those in Bergstrom. Blume and Varian (1986).

\section{Lemma 7 With identical preferences:}

(i) $\forall j, d_{j}^{p} \leq d_{j}^{s}$.

(ii) $\Omega^{p}\left(d_{0}^{s}\right) \leq 0$, so that $d_{0}^{s}<d_{0}^{u}$.

(iii) $\Omega^{n}\left(d_{0}^{p}\right) \leq 0$, so that $d_{0}^{l}<d_{0}^{p}$.

(i) Suppose. by way of contradiction. that for some $j, d_{j}^{p}>d_{j}^{s}$, which then implies $d_{j}^{p}>0$. Then by Lemma $4, h\left(w_{j}+D_{-j}^{p}\right)-D_{-j}^{p}>d_{j}^{p}>d_{j}^{s} \geq h\left(w_{j}+D_{-j}^{s}\right)-D_{-j}^{s}$. Then $D_{-j}^{p}<D_{-j}^{s}$, and since $d_{0}^{p}>d_{0}^{s}$, there must be some $k \neq 0 . j$ for which $0 \leq d_{i}^{p}<d_{j}^{s}$. Then we have $x^{p}=w_{j}-d_{j}^{p}<w_{j}-d_{j}^{s} \leq$ 
$x^{n}\left(d_{0}^{s}\right) \equiv x^{s}$. and $x^{p} \geq w_{k}-d_{k}^{p}>w_{k}-d_{k}^{s}=x^{s}$. a contradiction

(ii) Suppose not. so that for some $j, A_{j}^{p}\left(d_{0}^{s}\right)>U_{j}^{p}$. Then it must be that $d_{j}^{\prime} \equiv \arg \max _{d_{j}}\left\{u\left(w_{j}-\right.\right.$ $\left.\left.d_{j}, d_{0}^{s}+D_{-0 j}^{p}+d_{j}\right) \mid K_{j}\left(d_{0}^{s}, D_{-0 j}^{p}\right) \leq d_{j} \leq w_{j}\right\}$ satisfies $D^{\prime} \equiv d_{0}^{s}+D_{0 j}^{p}+d_{j}^{\prime}>\bar{D}\left(d_{0}^{s}\right)=D^{s}>D^{p}$ and $u\left(w_{j}-d_{j}^{\prime}, D^{\prime}\right)>u\left(w_{j}-d_{j}^{p}, D^{p}\right)$. Letting $D_{-j}^{\prime} \equiv d_{0}^{s}+D_{-0 j}^{p}$, we have $D^{\prime}=h\left(w_{j}+D_{-j}^{\prime}\right)>$ $D^{s} \geq h\left(w_{j}+D_{-j}^{s}\right)$, so $D_{-j}^{\prime}>D_{-j}^{s}$, and therefore there must be some $k \neq 0, j$ for whom $d_{k}^{p}>d_{k}^{s}$, contradicting (i).

(iii) We first prove two useful facts:

Fact $3 \delta_{j}^{n}\left(\alpha_{0}^{p}\right)>0$ implies $\delta_{j}^{n}\left(\alpha_{0}^{p}\right)>d_{j}^{p}$.

Suppose this is not so. Then $x^{n}\left(d_{0}^{p}\right)=w_{j}-\delta_{j}^{n}\left(d_{0}^{p}\right) \geq w_{j}-d_{j}^{p}$, and if $x^{p}>w_{j}-d_{j}^{p}$, then $d_{j}^{p}=0$, and $\delta_{j}^{n}\left(d_{0}^{p}\right)>d_{j}^{p}$, a contradiction. So it must be that $x^{p}=w_{j}-d_{j}^{p}$, hence $x^{n}\left(d_{0}^{p}\right) \geq x^{p}$, which means that $\delta_{k}^{n}\left(d_{0}^{p}\right) \leq w_{k}-x^{n}\left(d_{0}^{p}\right) \leq w_{k}-x^{p}, \forall k$. In particular, then, $\delta_{k}^{n}\left(d_{0}^{p}\right)>0$ implies that $d_{k}^{p}=w_{k}-x^{p} \geq$ $\delta_{k}^{n}\left(d_{0}^{p}\right)>0$, while $\delta_{k}^{n}\left(d_{0}^{p}\right)=0$ implies $d_{k}^{p} \geq \delta_{k}^{n}\left(d_{0}^{p}\right)$, so we get that $\Delta_{-0}^{n}\left(d_{0}^{s}\right)=D_{-0}^{s} \geq D_{-0}^{p} \geq \Delta_{-0}^{n}\left(d_{0}^{p}\right)$, so that $\Delta_{-0}^{n}($.$) being decreasing implies d_{0}^{s} \leq d_{0}^{p}$, contradicting Lemma 5 .

Fact $4 \delta_{j}^{n}\left(d_{0}^{p}\right)=0$ implies $d_{j}^{p}=0$

Suppose not, so that $w_{j}-x^{p}=d_{j}^{p}>0=\hat{\delta}_{j}^{n}\left(d_{0}^{p}\right) \geq w_{j}-x^{n}\left(d_{0}^{p}\right)$, so $x^{p}<x^{n}\left(d_{0}^{p}\right)$. So if any $\delta_{k}^{n}\left(d_{0}^{p}\right)>0$, then $\delta_{k}^{n}\left(d_{0}^{p}\right)=w_{k}-x^{n}\left(d_{0}^{p}\right)<w_{k}-x^{p}$, so if any $d_{k}^{p}>0$, then $d_{k}^{p}=w_{k}-x^{p}>\delta_{k}^{n}\left(d_{0}^{p}\right)$, contradicting Fact 1. So $\delta_{k}^{n}\left(d_{0}^{p}\right)>0$ must imply that $d_{k}^{p}=0$, and so $x^{n}\left(d_{0}^{p}\right)<w_{k}-x^{p}$, which is a contradiction. also.

Therefore it must be that all $\delta_{k}^{n}\left(d_{0}^{p}\right)=0$. so that $\Delta_{-0}^{n}\left(d_{0}^{p}\right)=0$, which would then imply that $\Omega^{n}\left(d_{0}^{p}\right) \leq 0$, as we are trying to prove. So suppose that some $\delta_{k}^{n}\left(d_{0}^{p}\right)>0$, so that Facts 3 and 4 must hold: 
We can now prove the Lemma.

Suppose that for some $j . \delta_{j}^{n}\left(d_{0}^{p}\right)>0$. and it pays $j$ to deviate down' to some $d_{j}^{\prime}<\delta_{j}^{n}\left(d_{0}^{p}\right)$. Then $d_{j}^{\prime}+\Delta_{-0 j}^{n}\left(d_{0}^{p}\right)<\bar{D}_{-0}\left(d_{0}^{p}\right)=D_{-0}^{p}$, and $D^{\prime}=h_{0}\left(w_{0}+d_{j}^{\prime}+\delta_{0 j}^{n}\left(d_{0}^{p}\right)\right)<h_{0}\left(w_{0}+D_{-0}^{p}\right)=D^{p}$. Then. since Facts 3 and 4 imply that $\Delta_{-0 j}^{n}\left(d_{0}^{p}\right) \geq D_{-0 j}^{p}$, it must be that $d_{j}^{t}<d_{j}^{p}$, and thus $d_{j}^{p}>0$. Then we have that $h_{j}\left(w_{j}+\Delta_{-0 j}^{n}\left(d_{0}^{p}\right)\right)+d_{0}^{p} \leq D^{\prime}<D^{p}=h_{j}\left(w_{j}+D_{-0 j}^{p}\right)+d_{0}^{p}$ and this implies that $\Delta_{-0 j}^{n}\left(d_{0}^{p}\right)<D_{0 j}^{p}$, a contradiction.

Proof. The results above establish that under identical preferences. it must be that $d_{0}^{u}$ and $d_{0}^{l} \in\left[d_{0}^{s}, d_{0}^{p}\right]$. All that remains te prove proposition 3 is to show that under these assumptions $d_{0}^{l}<d_{0}^{l}$

Note that affinely homothetic preferences imply that $h_{j}(y)=a_{j}\left(y-b_{j}\right)$ for some $a_{j}<1$, and any $y>b_{j}$. Thus, $h_{j}(y)=\arg \max _{D} u_{j}\left(y-p_{0} D, D\right)$, where $p_{0} \equiv 1 / a_{0}$. Further, the indirect utility function for any individual with such preferences can be written as $v_{j}\left(p, m_{j}\right)=\frac{m_{j}-\Lambda_{j}(p)}{\pi_{j}(p)}$, where $p$ is the relative price of $Z$. Thus we have that

$$
A_{j}^{p}=\frac{w_{j}+D_{-0 j}^{p}+\omega-\Lambda_{j}\left(p_{0}\right)}{\pi_{j}\left(p_{0}\right)}
$$

where $\omega=w_{0}^{\prime}-b_{0}$.

Identical $u_{j}($.$) and w_{j}$ imply that (dropping the $j$ subscript)

$$
\forall j, d_{j}^{p}=d^{p}=h\left(w+(n-1) d^{p}+\omega\right)-\left|d_{0}^{p}+(n-1) d^{p}\right|
$$

and that

$$
\forall j, C_{j}^{p}=U^{p}=\frac{w+(n-1) d^{p}+w-\Lambda\left(p_{0}\right)}{\pi\left(p_{0}\right)} \equiv \frac{I-\Lambda_{0}}{\pi_{0}}
$$

Further,

$$
A^{p}\left(d_{0}^{u}\right) \equiv \frac{w+(n-1) d^{p}+d_{0}^{u}-\Lambda(1)}{\pi(1)} \equiv \frac{I^{u}-\Lambda_{1}}{\pi_{1}}=U^{p} .
$$

To prove the result we need to show that $\Omega^{n}\left(d_{0}^{n}\right) \leq 0$. Now note that

$$
U_{j}^{n}\left(d_{0}^{u}\right) \equiv U^{u} \equiv \frac{w+(n-1) d^{u}+d_{0}^{u}-\Lambda_{1}}{\pi_{1}} \equiv \frac{J^{u}-\Lambda_{1}}{\pi_{1}}
$$

where $d^{u}=\delta^{n}\left(d_{0}^{u}\right)$, and also

$$
A_{j}^{n}\left(d_{0}^{u}\right) \equiv A^{u} \leq \frac{w+(n-1) d^{u}+\omega-\Lambda_{0}}{\pi_{0}} \equiv \frac{J-\Lambda_{0}}{\pi_{0}}
$$


Also note that $I^{u}-I=d_{0}^{u}-w=J^{u}-J$. It remains to show that $A^{u}<U^{u}$. but substituting the expression for $U^{p}$ into the one for $U^{u}$. and manipulating yields:

$$
\frac{J^{u}-\Lambda_{1}}{\pi_{1}}=\frac{J-\Lambda_{0}}{\pi_{0}}+\frac{\left(\pi_{0}-\pi_{1}\right)(J-I)}{\pi_{0} \pi_{1}} .
$$

Since $\pi($.$) is increasing, then \pi_{0}<\pi_{1}$, and the result follows if $(n-1) d^{u}=\Delta_{-0 j}^{n}\left(d_{0}^{u}\right)>D_{-0 j}^{p}=$ $(n-1) d^{p}$. However, we already demonstrated that with identical preferences alone, $\Delta_{-0 j}^{n}\left(d_{0}^{p}\right)>D_{-0 j}^{p}$, and since $d_{0}^{p}>d_{0}^{u}$ and $\Delta_{-0 i}^{n}()$ is decreasing, this must hold. 


\section{References}

Andreoni, J.(1988) 'Privately provided goods in a large economy: the limits of altruism: Journal of Public Economics 35, 57-73

Andreoni, J.(1989) 'Giving with impure altruism: applications to charity and Ricardian equivalence: Journal of Political Economy 97, 1447-57.

Ben-Ner, A. and Gui, B.(1993), 'Introduction' in A. Ben-Ner and B. Gui (Eds.), The Nonprofit Sector in the Mixed Economy, The University of Michigan Press, p.1-24

Bergstrom, T., Blume, L., and Varian, H.(1986) :On the private provision of public goods' Journal of Public Economics 29, 25-50.

Bernheim, D.(1986) 'On the voluntary and involuntary provision of public goods' American Economic Review 75, 789-93

Bilodeau, M., (1992) 'Voluntary contributions to united charities' Journal of Public Economics 48,119-33.

Bilodeau, M., (1993) 'Public goods provision institutions' in A. Breton, et. al. (eds.), Preferences and Democracy: International Studies in Economics and Econometrics Volume 28, Kluwer Academic Publishers, 135-155.

Bilodeau, M. and Slivinski, A.(1995a), 'Toilet Cleaning and Department Chairing: Volunteering a Public Service' Journal of Public Economics, forthcoming

Bilodeau, M. and Slivinski. A.(1995b), 'Volunteering Nonprofit Entrepreneurial Services:, Journal of Economic Behavior and Organization. forthcoming

Bilodeau, M. and Slivinski, A. (1995c), 'Rival Charities', mimeo Lniversité de Sherbrooke

Bilodeau, M. and Slivinski, A.(1995d), 'Profitable Lonprofit Enterprises', mimeo Université de Sherbrooke

Bliss, C. and Nalebuff, B. (1984) 'Dragon-slaying and ballroom dancing:the private supply of a public good' Journal of Public Economics 25, 1-12.

Breit, William(1968)'Public goods interaction in Stackelberg geometry' Western Economic Journal, 161-64.

Easley, D., and O'Hara, M..(1983) 'The economic role of non-profit firms' Bell Journal of Economics, 531-38.

Eckel, C. and Steinberg, R.(1993), "Tax Policy and the Objectives of Nonprofit Organizations", ARNOVA 1993 Conference Proceedings, p.92-97 
Fama. E. and Jensen, M.(1983) Agency problems and residual claims' Journal of Law and Economics 26. 327-50.

Gassler, R.(1990) '-ionprofit and voluntary economics: a critical survey' Nonprofit and Voluntary Sector Quarterly 19. 137-50.

Hall, P.(1987) 'A historical overview of the private nonprofit sector' in Powell, IV., (Ed.) The Nonprofit Sector: A Research Handbook Yale U'niversity Press.

Hansmann. H.(1980) 'The role of non-profit enterprise' Yale Law Journal 89, 835-98.

Hodgkinson, Virginia Ann et al(1992). Nonprofit Almanac 1992-1993, Dimensions of the Independent Sector, Jossey-Bass Publishers

James, E. and Rose-Ackerman. S.(1986) The Nonprofit Enterprise in Market Economies. Harwood Academic Publishers.

Rose-Ackerman, S.(1987) 'Ideals versus dollars: donors, charity managers, and government grants' Journal of Political Economy 95, 810-23.

Sugden, R.(1982) 'On the economics of philanthropy: The Economic Journal 92, 34150 .

Steinberg, R.(1993). 'Public Policy and the Performance of Nonprofit Organizations: A general Framework', Nonprofit and Voluntary Sector Quarterly, 22(1), 13-31.

Varian, H.(1994) 'Sequential provision of public goods', Journal of Public Economics $53,165-186$

Young, D.(1983) If not for profit, for what?, Lexington, MA: Heath

Weisbrod, B.(1975), 'Towards a Theory of the Voluntary Nonprofit Sector in a ThreeSector Economy:, in E. Phelps (Ed.) .Altruism. Morality and Economic Theory, Russell Sage Foundation: p.171-195.

Weisbrod. B.(1988) The Nonprofit Economy, Harvard University Press. 